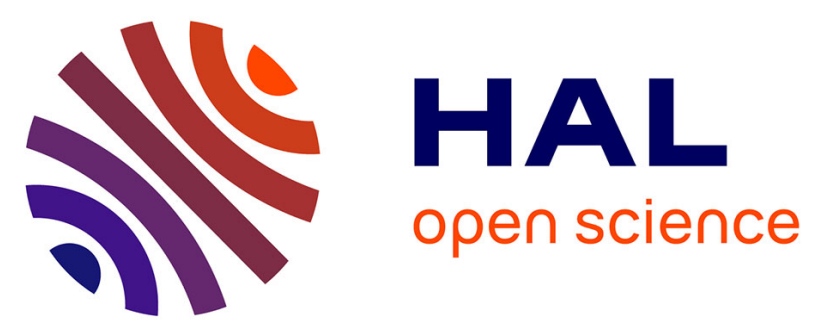

\title{
Non-thermal plasma treatment of volatile organic compounds: A predictive model based on experimental data analysis
}

Pedro H. Affonso Nobrega, Laurent Fulcheri, Vandad-Julien Rohani

\section{- To cite this version:}

Pedro H. Affonso Nobrega, Laurent Fulcheri, Vandad-Julien Rohani. Non-thermal plasma treatment of volatile organic compounds: A predictive model based on experimental data analysis. Chemical Engineering Journal, 2019, 364, pp.37-44. 10.1016/j.cej.2019.01.100 · hal-02406659

\section{HAL Id: hal-02406659}

https://hal-mines-paristech.archives-ouvertes.fr/hal-02406659

Submitted on 21 Oct 2021

HAL is a multi-disciplinary open access archive for the deposit and dissemination of scientific research documents, whether they are published or not. The documents may come from teaching and research institutions in France or abroad, or from public or private research centers.
L'archive ouverte pluridisciplinaire HAL, est destinée au dépôt et à la diffusion de documents scientifiques de niveau recherche, publiés ou non, émanant des établissements d'enseignement et de recherche français ou étrangers, des laboratoires publics ou privés.

\section{(ㄷ)(1) $\$$}

Distributed under a Creative Commons Attribution - NonCommerciall 4.0 International 


\title{
Non-thermal plasma treatment of volatile organic compounds: a predictive model based on experimental data analysis
}

\author{
P.H. Affonso Nóbrega ${ }^{\mathrm{a}, *}$, V. Rohani ${ }^{\mathrm{a}}$, L. Fulcheri ${ }^{\mathrm{a}}$ \\ ${ }^{a}$ MINES ParisTech, PSL Research University, PERSEE - Centre for processes, renewable \\ energy and energy systems, CS 10207 rue Claude Daunesse 06904 Sophia Antipolis Cedex, \\ France
}

\begin{abstract}
Non-thermal plasma is an emerging alternative for removing VOC from polluted air streams. This technique has been studied in laboratory for more than twenty years and experimental data is abundant. However, mostly qualitative information has been obtained from that data and no model has been developed for predicting the treatment performance from a given set of parameters. In this paper, we establish such a model, based on experimental data extracted from 69 scientific publications. This model, obtained through a linear regression, uses both quantitative and qualitative variables to predict the energy yield of the treatment. In $80 \%$ of the data points, the measured energy yield lies between 0.6 and 1.75 times the predicted value. We also used the model to evaluate quantitatively the impact of several parameters of the treatment, such as the initial concentration, the presence of a catalyst or the reactor type. Being so, the model presented here is an invaluable tool for both scientists and engineers interested in the treatment of VOC by non-thermal plasma.
\end{abstract}

${ }^{*}$ Corresponding author

Preprint submitted to Elsevier

December 28, 2018 
Keywords: Non-thermal plasma, Volatile organic compounds, Linear regression

\section{Introduction}

An emerging alternative for removing hazardous or odorous volatile organic compounds (VOC) from polluted air streams is the use of non-thermal plasma. It consists of using the reactive species produced in the plasma, such as $\mathrm{O}$ and $\mathrm{OH}$ radicals, to oxidize volatile organic compounds, mainly forming $\mathrm{CO}_{2}$ and $\mathrm{H}_{2} \mathrm{O}$. It is a flexible, compact and relatively cheap technique, which can be suitable for the treatment of low pollutant concentrations $[1,2]$.

The treatment of VOC by non-thermal plasma has been studied in laboratory for more than twenty years $[3-5]$ and has been the object of some pilot experiments [6-11]. Most published works follow the same approach: for a given set of experimental conditions, researchers vary the power dissipated in the plasma and measure the amount of VOC removed. Most often, results are presented in the form of plots of the VOC residual fraction as a function of the specific energy input. The residual fraction is given by the ratio between outlet concentration $C_{\text {out }}$ and inlet concentrations $C_{i n}$ :

$$
\text { Residual fraction }=\frac{C_{\text {out }}}{C_{\text {in }}}
$$

the specific energy input (SEI) is the ratio between the power dissipated in the plasma $P$ and the inlet flow rate $Q$ :

$$
\mathrm{SEI}=\frac{P}{Q}
$$


Researchers then repeat the same experiment while changing a given experimental parameter in order to isolate its impact on the residual fraction versus SEI curve. From those kinds of experiments, which have been repeated extensively for a wide range of experimental conditions, some review papers have extracted qualitative information on the impact of certain parameters, such as inlet gas temperature, humidity level, VOC concentration, flow rate and oxygen content $[5,12]$.

But in spite of the significant amount of experimental data produced in the last two decades, it is still difficult to say in a quantitative manner what is the impact of a given parameter. Further, no attempt has been done to predict the treatment performance under a given set of conditions based on the available data. For instance, if faced with the question "how much energy should I expect to spend to treat an air flow of $1000 \mathrm{~m}^{3} / \mathrm{h}$ containing $200 \mathrm{mg} / \mathrm{m}^{3}$ of ethanol?", one must look for available data with experimental conditions as close as possible to those considered. But this is no easy task, given the number of published studies and the variety of experimental parameters that could impact the treatment performance. In this paper, we try to address that lacuna.

As far as we know, no previous work has attempted to establish a predictive model based on the vast amount of experimental data available. Recent works even tried to extract quantitative information from available experimental data. For instance, Veeranpandian et al. [13] present an excellent review of experimental work using non-thermal plasma packed-bed reactors, but values 
of removal efficiency and specific energy input are presented in a table form and correspond to different values of flow rate, inlet concentration or packing characteristics, which hinders comparison. Ye et al. [14] use scatter plots to compare the performance of different experiments, but the scope of the review is limited to the treatment of toluene with post-plasma catalysis (PPC) configurations.

In this work, for the first time, we attempt to translate experimental data into a model consisting of a single formula predicting the performance of any VOC treatment by non-thermal plasma. The goal of this model is to use some readily available treatment parameters, such as the SEI, the inlet VOC concentration, the inlet gas temperature or the VOC type in order to obtain quantitative information on the expected performance of the treatment. Such information can be useful in a range of use cases:

- Preliminary design of a new non-thermal plasma reactor for VOC treatment: given a set of parameters, how much power should I expect to need?

- Benchmark of different non-thermal plasma reactors for VOC treatment: how efficient is my reactor compared to experimental data available in the literature?

- Analysis of the impact of a treatment parameter: given the experimental data available in the literature, what is the real effect of a given parameter on the treatment performance?

The two first use cases require the model to be straightforward and to use 
only readily available treatment parameters. For instance, a parameter such as the $\mathrm{OH}$ radical concentration in the discharge zone does impact treatment performance, but obtaining it requires complicated experimental means that are not available to many researchers and to most engineers. Using that parameter as input would certainly limit the model's use.

Simplicity also requires the model to have as few inputs as possible. This is a challenge because non-thermal plasma reactors for VOC treatment use a wide variety of configurations, geometries, materials and catalysts. In this work we attempted to carefully select input variables, keeping the description of reactor characteristics and experimental conditions as general as possible, in order to avoid an over-complicated model.

To obtain a single formula predicting the performance of VOC treatment by non-thermal plasma, we decided to use a linear regression model. The main reasons for this choice are that such models are simple, make it easy to interpret how inputs affect the output and can deal with both quantitative and qualitative variables. Further, numerical implementation is straightforward, since linear regression analysis methods are included in a number of computational packages and libraries.

In the following sections, we begin by describing the methods we used for collecting experimental data and describing experimental parameters and for building a linear regression model. We then present the obtained results and discuss them, from the selection of input variables and the estimation of regression coefficients to the establishment of a predictive formula and the analysis of 
its performance in the prediction of the treatment efficiency. We finally use the obtained formula to analyze the impact of different experimental parameters, just before concluding with some final remarks.

\section{Methods}

We analyzed 69 scientific papers and $\mathrm{PhD}$ thesis published between 1999 and 2018 [9, 10, 15-81]. From each study, we extracted series of measurements of VOC outlet concentration as a function of the specific energy input. Further, we built a relational database to store the experimental conditions corresponding to each data series. Then, we developed a linear regression model in order to predict the value of the specific energy input of the treatment from several independent variables, both qualitative and quantitative, defined from those experimental conditions. In the following, we describe how we collected data and how we used it to build a linear regression model.

\subsection{Data collection}

We looked for scientific papers or PhD thesis where experimental work on the treatment of VOC by non-thermal plasma is reported, and where VOC outlet concentrations are given as a function of the specific energy input or any equivalent parameter that could be converted to it, such as dissipated power or pulse repetition frequency ${ }^{1}$. We did not consider works where VOC mixtures are treated, but those constitute only a tiny part of the literature. After verifying that the description of the experimental set up was complete enough,

\footnotetext{
${ }^{1}$ The pulse repetition frequency can be converted to the specific energy input if the energy per pulse is known or can be deduced from the available information.
} 
we extracted measurements of outlet concentration as a function of the SEI manually, for a total amount of 1826 measurements. For that, we used a web application that allows one to retrieve coordinates of a point from the image of a plot [82]. We stored those measurements in parts per million (ppm) and J/L units, respectively, converting units whenever needed. Finally, we built a database record with parameters describing the experimental conditions. Those parameters are listed on table 1.

\subsubsection{Inlet conditions}

Inlet conditions included the treated VOC and its inlet concentration, the background gas composition, as well as the gas temperature, flow rate and pressure. The background gas composition included the absolute humidity. When not mentioned by the authors, we assumed the following conditions :

- Dry air composition : $80 \% \mathrm{~N}_{2}+20 \% \mathrm{O}_{2}$

- Gas temperature : $20^{\circ} \mathrm{C}$

- Gas pressure : $101325 \mathrm{~Pa}$

\subsubsection{Reactor characteristics}

Reactor characteristics included essentially the reactor type, the reactor volume and, if any, the catalyst used and its configuration. The reactor types were :

- surface DBD ;

- volume DBD ; 
Table 1: List of parameters stored in the database. These parameters describe the experimental conditions of the VOC treatment by non-thermal plasma.

\section{Inlet conditions}

Treated VOC

Inlet concentration

Background gas composition

Inlet temperature

Flow rate

Pressure

\section{Reactor characteristics}

Reactor type

Reactor volume

Catalyst

Catalyst configuration

\section{Electric parameters}

Signal type

\section{VOC characteristics}

Name

Family

Molar mass

Boiling point

Rate of reaction with $\mathrm{OH}$ at $298 \mathrm{~K}$ 
- packed-bed DBD ;

- corona ;

- other.

Reactor types classified as other include a photo-triggered discharge reactor used by Faider et al. [63] and hybrid surface/packed-bed reactors used by Jiang et al. $[52-54,57]$.

The reactor volume used was either the one given explicitly by the authors or calculated from the reactor dimensions provided. This volume correspond to the active part of the reactor where discharges take place. In our calculations, we considered this active part to be the section of the reactor covered by the external electrode. We classified the catalyst configuration as either in-plasma catalysis (IPC) or post-plasma catalysis (PPC).

\subsubsection{Electric parameters}

The only electrical parameter considered was the signal type : either alternate $(\mathrm{AC})$, nanosecond pulse $(\mathrm{NS})^{2}$ or microsecond pulse $(\mu \mathrm{S})$.

\subsubsection{VOC characteristics}

VOC characteristics include properties such as molar mass, boiling point and rate of the rate of its gas-phase reaction with the hydroxyl radical $(\mathrm{OH})$ and with ozone $\left(\mathrm{O}_{3}\right)$. Molar mass is an indicator of the molecule size, whereas the boiling point is related to its volatility. The rates of reaction with $\mathrm{OH}$ indicate

\footnotetext{
${ }^{2}$ We considered nanonsecond pulses as those pulses having a pulse width inferior to $10 \mu \mathrm{s}$. Otherwise, we used the microsecond pulse classification.
} 
how easily the VOC can be oxidized. These rates were taken from the NIST kinetics database [83].

\subsection{Linear regression model}

Our linear regression model has the form:

$$
y=\beta_{0}+\sum_{i} \beta_{i} x_{i}+\epsilon
$$

where $y$ is the independent variable, $x_{i}$ are the dependent variables, which can be either quantitative or qualitative, $\beta_{i}$ are the corresponding linear coefficients, and $\epsilon$ is a residual term. For the quantitative variables, we use a logarithmic base, as they may vary over several orders of magnitude.

As dependent variable, we take the logarithm of the energy yield in $\mathrm{g} / \mathrm{kWh}$ :

$$
y=\log _{10} \mathrm{EY}
$$

The energy yield is defined for each data point as the mass of VOC removed per energy unit dissipated in the plasma:

$$
\mathrm{EY}=\frac{C_{\text {in }}-C_{\text {out }}}{\mathrm{SEI}}
$$

It is calculated for each data point and has been chosen because it is directly related to the sizing of a non-thermal plasma treatment : the mass of VOC emitted per unity time divided by the energy yield gives the plasma power needed.

Independent variables were defined from experimental conditions and listed in tables 2 and 3. Qualitative variables have a unity value if the data point belong to the corresponding category or a zero value otherwise. For instance, if 
the inlet air is humid, $x_{9}=1$.

We used a least squares method to obtain the values of $\beta_{i}$ corresponding to each independent variable. We then proceeded with a backward selection of independent variables where, at each step, the least significant variable is removed from the model. The significance of the $i$-th independent variable is given by a statistical test whose null hypothesis is $\beta_{i}=0$. We stop the selection when all the variables have a $p$-value ${ }^{3}$ lower than 0.05 (an arbritary criterium typically used for statistical tests). Both the least squares and the backward selection methods used are discribed in detail in [84].

The implementation of the least squares model used the OLS module of the StatsModels library for Python [85]. This module provides methods for computing regression coefficients and their standard errors, confidence intervals and $p$-values used in this work.

It should be noted that the result of the linear regression model can be seen as the conditional expected value of the independent variable given the set of dependent variables. In our case, the model can be seen as the conditional expected value of the (logarithm of) the energy yield given the quantitative and qualitative variables describing the experimental conditions. This conditional expected value does say anything about the variability of the energy yield, which is related to the residual term $\epsilon$ in equation 3. This variability can be related

\footnotetext{
${ }^{3}$ The $p$-value is the probability of observing a given result provided the null hypothesis is true. A small $p$-value indicates that the evidence that $\beta_{i}$ is different from zero is strong. Conversely, a large $p$-value indicates that the evidence that $\beta_{i}$ is different from zero is weak. $\beta_{i}=0$ means that the corresponding variable has no impact in the model's prediction. Removing variables with $p$-value above 0.05 implies that we only retain those variables for which we have strong evidence that $\beta_{i}$ is different from zero.
} 
Table 2: Independent quantitative variables.

\begin{tabular}{clcc}
\hline Variable & Description & Value & Unity* \\
\hline$x_{1}$ & Initial concentration & $\log _{10} C_{i n}$ & $\mathrm{~g} / \mathrm{m}^{3}$ \\
$x_{2}$ & Specific energy input & $\log _{10} \mathrm{SEI}$ & $\mathrm{J} / \mathrm{L}$ \\
$x_{3}$ & Molar mass & $\log _{10} W$ & $\mathrm{~g} / \mathrm{mol}$ \\
$x_{4}$ & Rate constant $-\mathrm{OH}$ & $\log _{10} k_{\mathrm{OH}}$ & $\mathrm{cm}^{3} / \mathrm{s}$ \\
$x_{5}$ & Inlet temperature & $\log _{10} T$ & $\mathrm{~K}$ \\
$x_{6}$ & Flow rate & $\log _{10} Q$ & $\mathrm{~L} / \mathrm{min}$ \\
$x_{7}$ & Reactor volume & $\log _{10} V_{R}$ & $\mathrm{~m}$ \\
$x_{8}$ & Boiling point & $\log _{10} T_{b}$ & $\mathrm{~K}$ \\
\hline
\end{tabular}

* Before logarithmic transform.

to different factors which are not taken into account in the set of dependent variables we use: experimental errors, different reactor geometries and materials, different electrical parameters such as voltage amplitude or pulse frequency, different dielectric materials for dielectric barrier discharges, different catalysts used. An analysis of those residual terms will be performed in section 3.4.

\section{Results and discussion}

\subsection{Backward selection}

The table 4 gives the variables which were removed by backward selection and the respective $p$-values justifying their removal. The only quantitative variable removed was the VOC boiling point. Qualitative variables removed were the VOC families alkane $\left(x_{10}\right)$ and aromatic $\left(x_{12}\right)$, reactor types volume $\left(x_{19}\right)$ 
Table 3: Independent qualitative variables.

\begin{tabular}{|c|c|c|}
\hline Variable & Description & Category \\
\hline$x_{9}$ & & Humid air \\
\hline$x_{10}$ & \multirow{9}{*}{ VOC family } & Alkane \\
\hline$x_{11}$ & & Alkene/Alkyne \\
\hline$x_{12}$ & & Aromatic \\
\hline$x_{13}$ & & Alcohol \\
\hline$x_{14}$ & & Aldehyde \\
\hline$x_{15}$ & & Ketone \\
\hline$x_{16}$ & & Sulphur \\
\hline$x_{17}$ & & Halogen \\
\hline$x_{18}$ & & Ether/Ester \\
\hline$x_{19}$ & \multirow{5}{*}{ Reactor type } & Volume DBD \\
\hline$x_{20}$ & & Surface DBD \\
\hline$x_{21}$ & & Packed-bed DBD \\
\hline$x_{22}$ & & Corona \\
\hline$x_{23}$ & & Other \\
\hline$x_{24}$ & \multirow{3}{*}{ Signal type } & $\mathrm{AC}$ \\
\hline$x_{25}$ & & NS pulse \\
\hline$x_{26}$ & & $\mu \mathrm{S}$ pulse \\
\hline$x_{27}$ & \multirow{3}{*}{ Catalysis } & No catalyst \\
\hline$x_{28}$ & & IPC \\
\hline$x_{29}$ & & $\mathrm{PPC}$ \\
\hline
\end{tabular}


and packed-bed DBD $\left(x_{27}\right)$, no catalyst and humid air $\left(x_{19}\right)$. The VOC family aromatic and humid air variables were removed with $p$-values close to the criterium value of 0.05 . Whether to include them in the model or not could be subject to discussion. We decided to stick to the 0.05 and not to include them for the sake of simplicity.

Table 4: Variables removed by backward selection.

\begin{tabular}{clc}
\hline Variable & Description & $p$-value \\
\hline$x_{8}$ & Boiling point & 0.965 \\
$x_{24}$ & AC & 0.767 \\
$x_{10}$ & Alkane & 0.758 \\
$x_{19}$ & Volume DBD & 0.127 \\
$x_{21}$ & Packed-bed DBD & 0.867 \\
$x_{12}$ & Aromatic & 0.087 \\
$x_{27}$ & No catalyst & 0.889 \\
$x_{9}$ & Humid air & 0.066 \\
\hline
\end{tabular}

\subsection{Regression coefficients}

Tables 5 and 6 give the coefficients $\beta_{i}$ obtained for the remaining variables, the corresponding standard errors and $95 \%$ confidence intervals. Interpretation of the obtained coefficients differs between quantitative and qualitative variables. For a quantitative variable $x_{i}$, the energy yield predicted by the model will be multiplied by $10^{\beta_{i}}$ when $x_{i}$ is multiplied by 10 . Therefore, a value of $\beta_{i}$ greater (lower) than zero implies that an increase of $x_{i}$ has a positive (negative) effect on 
the energy yield. For a qualitative variable, the energy yield will be multiplied by $10^{\beta_{i}}$ if the corresponding category applies. For instance, if the VOC is an alcohol $\left(x_{13}\right)$, the energy yield is multiplied by $10^{0.17}=1.48$. On the other hand, if the VOC is a ketone, the energy yield is multiplied by $10^{-0.18}=0.66$.

Table 5: Coefficients obtained for independent quantitative variables.

\begin{tabular}{clrrr}
\hline Variable & Description & Value & $\begin{array}{r}\text { Std. } \\
\text { Error }\end{array}$ & $\begin{array}{r}95 \% \text { Confidence } \\
\text { Interval }\end{array}$ \\
\hline$\beta_{0}$ & Intercept & 0.7 & 0.3 & {$[0.1,1.4]$} \\
$\beta_{1}$ & Initial concentration & 0.76 & 0.01 & {$[0.74,0.79]$} \\
$\beta_{2}$ & Specific energy input & -0.70 & 0.01 & {$[-0.72,-0.68]$} \\
$\beta_{3}$ & Molar mass & 0.22 & 0.07 & {$[0.08,0.36]$} \\
$\beta_{4}$ & Rate constant - OH & 0.05 & 0.01 & {$[0.02,0.08]$} \\
$\beta_{5}$ & Inlet temperature & 0.70 & 0.08 & {$[0.55,0.85]$} \\
$\beta_{6}$ & Inlet flow rate & -0.026 & 0.008 & {$[-0.032,-0.015]$} \\
$\beta_{7}$ & Reactor volume & -0.023 & 0.004 & {$[-0.042,-0.010]$} \\
\hline
\end{tabular}

\subsection{Predictive formula}

Since we used a logarithmic transform, to obtain those coefficients, the model could be rewritten under the form:

$$
\mathrm{EY}_{\text {model }}=5 \frac{C_{i n}^{0.76} W^{0.22} k_{\mathrm{OH}}^{0.05} T^{0.70}}{\mathrm{SEI}^{0.70} Q^{0.026} V_{R}^{0.023}}
$$

Equation 6 takes as input (right-hand side) the numerical values of the corresponding quantitative variables when they are expressed in the units given in table 2 and returns the numerical value of the predicted energy yield $\mathrm{EY}_{\text {model }}$ in 
Table 6: Coefficients obtained for independent qualitative variables.

\begin{tabular}{clccr}
\hline Variable & Description & Value & $\begin{array}{r}\text { Std. } \\
\text { Error }\end{array}$ & $\begin{array}{r}95 \% \text { Confidence } \\
\text { Interval }\end{array}$ \\
\hline$\beta_{11}$ & Alkene/Alkyne & 0.18 & 0.04 & {$[0.10,0.26]$} \\
$\beta_{13}$ & Alcohol & 0.17 & 0.03 & {$[0.12,0.22]$} \\
$\beta_{14}$ & Aldehyde & 0.09 & 0.03 & {$[0.04,0.14]$} \\
$\beta_{15}$ & Ketone & -0.18 & 0.02 & {$[-0.22,-0.14]$} \\
$\beta_{16}$ & Sulphur & 0.22 & 0.03 & {$[0.16,0.29]$} \\
$\beta_{17}$ & Halogen & 0.16 & 0.04 & {$[0.09,0.23]$} \\
$\beta_{18}$ & Ether/Ester & -0.20 & 0.03 & {$[-0.26,-0.14]$} \\
$\beta_{20}$ & Surface DBD & 0.09 & 0.02 & {$[0.06,0.13]$} \\
$\beta_{22}$ & Corona & 0.13 & 0.02 & {$[0.09,0.17]$} \\
$\beta_{23}$ & Other & 0.08 & 0.02 & {$[0.03,0.12]$} \\
$\beta_{25}$ & NS pulse & 0.04 & 0.02 & {$[0.01,0.08]$} \\
$\beta_{26}$ & $\mu S$ pulse & 0.23 & 0.04 & {$[0.16,0.30]$} \\
$\beta_{28}$ & IPC & 0.06 & 0.01 & {$[0.04,0.09]$} \\
$\beta_{29}$ & PPC & 0.24 & 0.02 & {$[0.20,0.29]$} \\
\hline
\end{tabular}


$\mathrm{g} / \mathrm{kWh}$. The value returned by equation 6 must be multiplied by the correction factors given in table 7, corresponding to the qualitative variables.

Table 7: Correction factors for equation 6 corresponding to the qualitative variables.

\begin{tabular}{|c|c|c|}
\hline & $\begin{array}{r}\text { Correction } \\
\text { factor } \\
\end{array}$ & $\begin{array}{r}95 \% \text { Confidence } \\
\text { Interval }\end{array}$ \\
\hline If the VOC is an alkene or alkyne: & $\times 1.51$ & {$[1.43,1.59]$} \\
\hline If the VOC is an alcohol: & $\times 1.48$ & {$[1.42,1.52]$} \\
\hline If the VOC is an aldehyde: & $\times 1.23$ & {$[1.18,1.28]$} \\
\hline If the $\mathrm{VOC}$ is a ketone: & $\times 0.66$ & {$[0.62,0.70]$} \\
\hline If the VOC is a sulphur compound: & $\times 1.66$ & {$[1.62,1.75]$} \\
\hline If the VOC is a halogen compound: & $\times 1.45$ & {$[1.36,1.51]$} \\
\hline If the VOC is an ether or an ester: & $\times 0.63$ & {$[0.58,0.69]$} \\
\hline If the reactor uses surface DBD: & $\times 1.23$ & {$[1.20,1.27]$} \\
\hline If the reactor uses corona discharges: & $\times 1.35$ & {$[1.31,1.39]$} \\
\hline If the reactor uses another type of discharge: & $\times 1.20$ & {$[1.15,1.23]$} \\
\hline If the reactor uses NS pulses: & $\times 1.10$ & {$[1.07,1.14]$} \\
\hline If the reactor uses $\mu S$ pulses: & $\times 1.70$ & {$[1.62,1.76]$} \\
\hline If the reactor uses in-plasma catalysis: & $\times 1.15$ & {$[1.12,1.18]$} \\
\hline If the reactor uses post-plasma catalysis: & $\times 1.74$ & {$[1.70,1.79]$} \\
\hline
\end{tabular}

A correction factor greater than unity implies that the corresponding category has a positive effect on the predicted energy yield. For instance, the use of nanosecond pulses the energy yield is multiplied by 1.10. If an AC signal is used, no correction factor is applied. Therefore the use of nanosecond pulses is 
expected to be $10 \%$ more efficient than the use of an AC signal. On the other hand, a correction factor lower than unity implies a lower predicted energy yield.

\subsection{Prediction performance}

Figure 1 shows the comparison between the values of the energy yield calculated for each data point with equation 5 and predicted by the model with equation 6 . We can see that the points follow quite closely the $\mathrm{EY}=\mathrm{EY}_{\text {model }}$. A more objective comparison is shown in figure 2, where a histogram of the

logarithm of the ratio between $\mathrm{EY}$ and $\mathrm{EY}_{\text {model }}$ is given. It should be noticed that the logarithm of the ratio between $\mathrm{EY}$ and $\mathrm{EY}_{\text {model }}$ is also the residual term $\epsilon$ of equation 3 , since $\log (A / B)=\log A-\log B$. We can see that most of the points have residuals between -0.5 and 0.5 , which correspond to ratios of 0.32 and 3.2. However, we notice some asymmetry, with a tendency of the model to overestimate EY, as indicated by the larger tail around -0.5 . This tendency may be observed visually in figure 1 too.

In figure 3, we show the percentiles of the ratio $\mathrm{EY} / \mathrm{EY}_{\text {model }}$. We can see that percentiles $10 \%$ and $90 \%$ are equal to 0.6 and 1.75 , respectively. That means that in $80 \%$ of the cases, the true value of the energy yield EY lies between 0.6 and 1.75 times the value predicted by the model, $\mathrm{EY}_{\text {model }}$. Therefore, we can say that the model performs very well in predicting the order of magnitude of the energy yield calculated for experimental data points, which can vary from values as low as $0.1 \mathrm{~g} / \mathrm{kWh}$ to $1000 \mathrm{~g} / \mathrm{kWh}$, i.e. across four orders of magnitude. However, even though the model is able to predict the order of magnitude of 
the energy yield, it is hard to exclude the occurrence of significant disparities between its true value and the predicted value, in other words, of high values of the residual term $\epsilon$. For instance, the $90 \%$ percentile indicates that for $10 \%$ of the occurrences the true value is 1.75 times higher than the predicted value. Such a disparity could be linked to experimental parameters which have not been taken into account in our model, such as catalyst nature or discharge characteristics.

But the disparity between true and predicted energy yield values can be useful. Indeed, it can be used to benchmark the treatment efficiency of a given reactor. If the true energy yield is higher (lower) than the predicted one, it means that some of the experimental parameters which are not taken into account in the model may increase (decrease) the treatment efficiency. That increase or decrease could be due, for instance, to a given type of catalyst or a particular electrode configuration.

To sum up, the linear regression model is able to predict an order of magnitude of the energy yield. As mentioned in section 2.2, the output of the model can be seen as a conditional expected value for this energy yield, given the experimental conditions used as input. However, the model does not exclude the occurrence of disparities between true and predicted values, which can be linked to aspects not taken into account in the model for the sake of simplicity.

\subsection{Impact of experimental parameters}

The coefficients obtained for both quantitative and qualitative variables give us a quantitative evaluation of the impact of each of those variables. We describe 


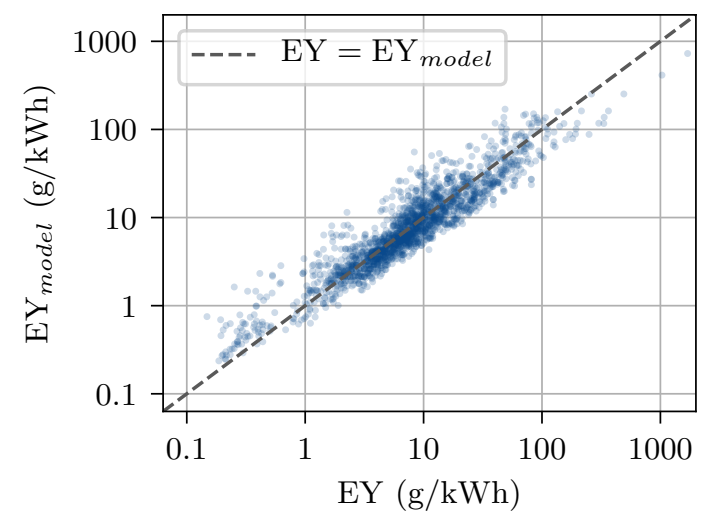

Figure 1: Comparison between the values of the energy yield calculated for each data point $(\mathrm{EY})$ and predicted by the model $\left(\mathrm{EY}_{\text {model }}\right)$.

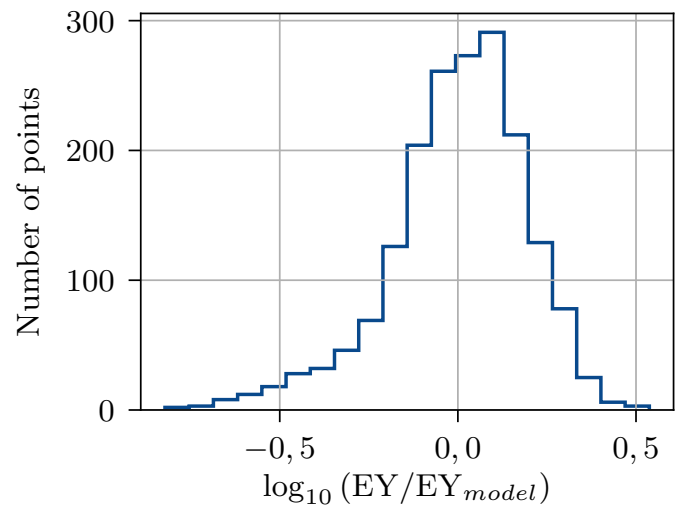

Figure 2: Histogram of the logarithm of the ratio between the values of the energy yield calculated for each data point (EY) and predicted by the model $\left(\mathrm{EY}_{\text {model }}\right)$. 
those impacts in the following.

\subsubsection{Initial concentration}

The energy yield increases with the initial concentration, more precisely with $C_{i n}^{0.76}$. That means that if we double the inlet concentration, we should expect an increase of $70 \%$ in the energy yield. This result is in agreement with previous experimental work, which identified an increase of the energy yield with the initial concentration $[10,22,28,56,86]$.

\subsubsection{Temperature}

The energy yield increases with the inlet temperature following $T^{0.70}$. This is related to a better process efficiency at high temperatures, as oxidation reaction rates increase and ozone formation, responsible for a significant loss of oxygen radicals, decreases. The increase of the treatment efficiency with temperature has been identified by several authors [37, 43, 68-70, 87].

\subsubsection{Humidity}

We notice that humidity has not been included in the model, the qualitative variable humid air $\left(x_{9}\right)$ having been removed with a $p$-value higher than 0.05 . Statistically, that means that there is not enough data evidence to support the hypothesis of a positive or negative impact of the presence of humidity. Indeed, experimental results vary, with some authors indicating that an optimum humidity levels exist [22, 43, 65, 72], while others indicate that humidity increases $[42,56]$ or decreases $[32,88]$ the treatment efficiency. 


\subsubsection{Flow rate and reactor volume}

Our model indicates that significant changes in the inlet flow rate and in the reactor volume may impact the performance of the treatment. Indeed, exponents for those parameters are respectively -0.026 and -0.023 . That means that multiplying the flow rate by 10 , the energy yield is reduced by $6 \%$. Similarly, multiplying the volume of the reactor by 10 implies a $5 \%$ reduction in the energy yield. Although these effects are small, they can play an important role in the process scale-up: increasing both the flow rate and the volume by a factor $\times 100$ implies a reduction of $20 \%$ in the energy yield.

\subsubsection{Organic compound}

The treatment efficiency varies with the VOC being destroyed. Our model indicates that VOCs with higher rates of oxidation reaction by the radical $\mathrm{OH}$ tend to be treated with higher energy yields. This behavior is quite logical, since the treatment is based on the action of oxidant species such as $\mathrm{O}$ and $\mathrm{OH}$ produced in the plasma. But the energy yield varies also with the VOC family. From the coefficients for qualitative variables (table 6), we can say that energy yield decreases in the following order :

$$
\begin{aligned}
& \text { sulphur }>\text { alkene/alkyne }>\text { alcohol }>\text { halogen }>\ldots \\
& \ldots>\text { aldehyde }>\text { alkane/aromatic }>\text { ketone }>\text { ether } / \text { ester }
\end{aligned}
$$

\subsubsection{Discharge type}

The energy yield is higher for surface DBD and corona discharge reactors.

Indeed, as we have seen, in those cases the energy yield given by equation 6 
is multiplied by 1.23 and 1.35 , respectively. That means that, energy yields for surface DBD and corona discharges are, on average, $23 \%$ and $35 \%$ than those for volume or packed-bed DBD reactors, given the same conditions. It should be noted that specific reactor geometries such as cylindrical or plane DBD configurations, electrodes types and materials, dielectric materials in DBD and packing characteristics in packed-bed DBD reactors have not been taken into account, for the sake of simplicity. Those aspects can be responsible for disparities between the true value of the energy yield and the one predicted by the model, as discussed in section 3.4.

\subsubsection{Signal type}

The energy yield must be multiplied by 1.10 when nanosecond pulses are used. This $10 \%$ increase with respect to when an AC signal is used corroborates the findings of Chiper et al. [66], who show that $160 \mathrm{ppm}$ of 2-heptanone are more efficiently converted by a DBD with nanosecond pulses rather than with an alternative signal.

Interestingly, the use of microsecond pulses (pulse width superior to $10 \mu \mathrm{s}$ ) seems to be very efficient, with a coefficient of 1.70 . However, only three papers in our review use this kind of signal $[20,24,28]$. More data would be needed to confirm this trend.

\subsubsection{Catalysis}

In accord with the litterature [89], the coupling with plasma and catalysts improves the energy yield. However, we found coefficients of 1.15 for in-plasma catalysis and 1.74 for post-plasma catalysis, which indicate that the latter con- 
figuration is generally more efficient. This result should be considered cautiously as we didn't take into account the catalyst used, but only whether a catalyst was used or not. Indeed, catalyst performance is directly impacted not only by the catalyst composition, but also by the fabrication process which impact the catalyst structure and the amount of catalyst used, related to the gas-hourly space velocity. Therefore, those parameters certainly impact VOC removal. However, taking them into account would increase considerably the complexity of the model and of data collection. Being so, we decided not to include those parameters in the scope of this work. The particular performance of a given catalyst can be reflected in the disparity between true and predicted values for the energy yield, as discussed in section 3.4.

\section{Conclusion}

In this paper, we have established a regression model for predicting the performance of the non-thermal plasma treatment of VOC. This model is based on series of measurements of VOC outlet concentration as a function of the specific energy input, extracted from 69 scientific publications. It takes as input variables such as the initial VOC concentration, the flow rate, the volume of the reactor, the VOC type or the use of a catalyst and return the expected energy yield, a measure of the treatment efficiency. In $80 \%$ of the data points, the calculated energy yield for the experimental data lies between 0.6 and 1.75 times the value predicted by the model. The model also allowed us to evaluate quantitatively the impact of several parameters of the treatment.

We believe that the model presented here will be of great value for anyone in- 
terested in the treatment of VOC by non-thermal plasma. Scientists performing experimental work will find it useful as a benchmark to which compare its own results. Engineers looking for a preliminary estimate of a non-thermal plasma treatment will also be able to use it.

In the future, we hope to keep our database up to date, including new experimental results to update the model's coefficients and/or to further validate the model. We also hope to extend the model to other aspects of non-thermal plasma treatment, such as ozone production or $\mathrm{CO}_{2}$ selectivity. Finally, we believe that the approach used here could be applied to other environmental applications of non-thermal plasmas, such as plasma-assisted reforming or $\mathrm{CO}_{2}$ conversion.

\section{Acknowledgements}

Pedro Affonso Nobrega thanks the Provence-Alpes-Côte d'Azur (PACA) region for its contribution to his $\mathrm{PhD}$ scholarship.

\section{References}

[1] S. Preis, D. Klauson, A. Gregor, Potential of electric discharge plasma methods in abatement of volatile organic compounds originating from the food industry, Journal of Environmental Management 114 (2013) 125-138. doi:10.1016/j.jenvman.2012.10.042.

[2] S. Ma, Y. Zhao, J. Yang, S. Zhang, J. Zhang, C. Zheng, Research progress of pollutants removal from coal-fired flue gas using non-thermal 
plasma, Renewable and Sustainable Energy Reviews 67 (2017) 791-810. doi:10.1016/j.rser.2016.09.066.

[3] T. Oda, R. Yamashita, I. Haga, T. Takahashi, S. Masuda, Decomposition of gaseous organic contaminants by surface discharge induced plasma chemical processing-SPCP, IEEE Transactions on Industry Applications 32 (1) (1996) 118-124. doi:10.1109/28.485822.

[4] Y. S. Mok, C. M. Nam, M. H. Cho, I. S. Nam, Decomposition of volatile organic compounds and nitric oxide by nonthermal plasma discharge processes, IEEE Transactions on Plasma Science 30 (1) (2002) 408-416. doi:10.1109/TPS.2002.1003889.

[5] A. M. Vandenbroucke, R. Morent, N. De Geyter, C. Leys, Non-thermal plasmas for non-catalytic and catalytic VOC abatement., Journal of Hazardous Materials 195 (2011) 30-54. doi:10.1016/j.jhazmat.2011.08.060.

[6] K. B. Andersen, J. A. Beukes, A. Feilberg, Non-thermal plasma for odour reduction from pig houses A pilot scale investigation, Chemical Engineering Journal 223 (2013) 638-646. doi:10.1016/j.cej.2013.02.106.

[7] A. Mizuno, Industrial applications of atmospheric non-thermal plasma in environmental remediation, Plasma Physics and Controlled Fusion 49 (2007) A1-A15. doi:10.1088/0741-3335/49/5A/S01.

[8] D. Almarcha, M. Almarcha, E. Jimenez-coloma, L. Vidal, I. Barrutiabengoa, Treatment Efficiency by means of a Nonthermal Plasma Combined 
with Heterogeneous Catalysis of Odoriferous Volatile Organic Compounds Emissions from the Thermal Drying of Landfill Leachates, Journal of Engineering 2014 (831584) (2014) 1-9.

[9] A. A. Assadi, A. Bouzaza, D. Wolbert, Comparative study between laboratory and large pilot scales for VOC's removal from gas streams in continuous flow surface discharge plasma, Chemical Engineering Research and Design 106 (2016) 308-314. doi:10.1016/j.cherd.2015.12.025.

[10] N. Mericam-Bourdet, Recherche d'optimisation énergétique d'un réacteur plasma froid de traitement d'effluents gazeux chargés en composés organiques volatils à pression atmosphérique, Thse de doctorat, Supéléc (2012).

[11] M. Holub, R. Brandenburg, H. Grosch, S. Weinmann, B. Hansel, Plasma Supported Odour Removal from Waste Air in Water Treatment Plants : An Industrial Case Study, Aerosol and Air Quality Research 14 (2014) 697-707. doi:10.4209/aaqr.2013.05.0171.

[12] G. Xiao, W. Xu, R. Wu, M. Ni, C. Du, X. Gao, Z. Luo, K. Cen, Non-thermal plasmas for VOCs abatement, Vol. 34, 2014. doi:10.1007/s11090-014-95620.

[13] S. K. P. Veerapandian, C. Leys, N. D. Geyter, R. Morent, Abatement of VOCs Using Packed Bed Non-Thermal Plasma Reactors : A Review, Catalysts 7 (113) (2017) 1-33. doi:10.3390/catal7040113. 
[14] Z. Ye, J.-M. Giraudon, N. De Geyter, R. Morent, J.-F. Lamonier, The Design of $\mathrm{MnO}_{\mathrm{x}}$ Based Catalyst in Post-Plasma Catalysis Configuration for Toluene Abatement, Catalysts 8 (91) (2018) 1-32. doi:10.3390/catal8020091.

[15] X. Zhu, S. Zhang, Y. Yang, C. Zheng, J. Zhou, X. Gao, Enhanced performance for plasma-catalytic oxidation of ethyl acetate over $\mathrm{La}_{1-x} \mathrm{Ce}_{x} \mathrm{CoO}_{3+\delta}$ catalysts, Applied Catalysis B, Environmental 213 (2017) 97-105. doi:10.1016/j.apcatb.2017.04.066.

[16] X. Zhu, X. Gao, X. Yu, C. Zheng, X. Tu, Catalyst screening for acetone removal in a single-stage plasma-catalysis system, Catalysis Today 256 (2015) 108-114. doi:10.1016/j.cattod.2015.01.028.

[17] C. Zhu, Y. Liu, J. Lu, Z. Yang, Y. Li, T. Chen, Decomposition of Ethanethiol Using Dielectric Barrier Discharge Combined with 185 nm UVLight Technique, Plasma Chemistry and Plasma Processing 35 (2) (2015) 355-364. doi:10.1007/s11090-014-9609-2.

[18] C. Zheng, X. Zhu, X. Gao, L. Liu, Q. Chang, Z. Luo, Experimental study of acetone removal by packed-bed dielectric barrier discharge reactor, Journal of Industrial and Engineering Chemistry 20 (5) (2014) 2761-2768. doi:10.1016/j.jiec.2013.11.004.

[19] M. Zadeh, Étude d'une pompe active EHD basée sur la mise en œuvre de décharges de surface pour le traitement des effluents gazeux d'origine 
industrielle, Thse de doctorat, École Nationale Supérieure des Mines de Paris (2014).

[20] S. Yao, S. Weng, Q. Jin, H. Lu, Z. Wu, X. Zhang, J. Han, Mechanism of Decane Decomposition in a Pulsed Dielectric Barrier Discharge Reactor, IEEE Transaction on Plasma Science 44 (11) (2016) 2660-2666.

[21] X. Xu, J. Wu, W. Xu, M. He, M. Fu, L. Chen, Highefficiency non-thermal plasma-catalysis of cobalt incorporated mesoporous MCM-41 for toluene removal, Catalysis Today 281 (2017) 527-533. doi:10.1016/j.cattod.2016.03.036.

[22] N. Xu, W. Fu, C. He, L. Cao, Benzene Removal Using Non-thermal Plasma with $\mathrm{CuO} / \mathrm{AC}$ Catalyst: Reaction Condition Optimization and Decomposition Mechanism, Plasma Chemistry and Plasma Processing (2014) 13871402doi:10.1007/s11090-014-9580-y.

[23] Z. Wu, Z. Zhu, X. Hao, W. Zhou, J. Han, X. Tang, S. Yao, X. Zhang, Enhanced oxidation of naphthalene using plasma activation of $\mathrm{TiO}_{2}$ /diatomite catalyst, Journal of Hazardous Materials 347 (2018) 48-57. doi:10.1016/j.jhazmat.2017.12.052.

[24] Z. Wu, J. Wang, J. Han, S. Yao, S. Xu, P. Martin, Naphthalene Decomposition by Dielectric Barrier Discharges at Atmospheric Pressure, IEEE Transactions on Plasma Science 45 (1) (2017) 154-161. doi:10.1109/TPS.2016.2632154. 
[25] J. Wu, Y. Huang, Q. Xia, Z. Li, Decomposition of Toluene in a Plasma Catalysis System with $\mathrm{NiO}, \mathrm{MnO}_{2}, \mathrm{CeO}_{2}, \mathrm{Fe}_{2} \mathrm{O}_{3}$, and $\mathrm{CuO}$ Catalysts, Plasma Chemistry and Plasma Processing 33 (2013) 1073-1082. doi:10.1007/s11090-013-9485-1.

[26] B. Wang, C. Chi, M. Xu, C. Wang, D. Meng, Plasma-catalytic removal of toluene over $\mathrm{CeO}_{2}-\mathrm{MnO}_{\mathrm{x}}$ catalysts in an atmosphere dielectric barrier discharge, Chemical Engineering Journal 322 (2017) 679-692. doi:10.1016/j.cej.2017.03.153.

[27] A. M. Vandenbroucke, M. Mora, C. Jiménez-sanchidrián, F. J. Romerosalguero, N. De Geyter, C. Leys, R. Morent, TCE abatement with a plasmacatalytic combined system using $\mathrm{MnO}_{2}$ as catalyst, Applied Catalysis B, Environmental 156-157 (2014) 94-100. doi:10.1016/j.apcatb.2014.03.007.

[28] K. Takaki, J. Nishimura, S. Koide, Decomposition of Ethylene Using Dual-Polarities Pulsed Dielectric Barrier Discharge, IEEE Transactions on Plasma Science 43 (10) (2015) 3476-3482.

[29] C. Subrahmanyam, A. Renken, Catalytic abatement of volatile organic compounds assisted by non-thermal plasma - Part II. Optimized catalytic electrode and operating conditions, Applied Catalysis B: Environmental 65 (2006) 157-162. doi:10.1016/j.apcatb.2006.02.024.

[30] C. Subrahmanyam, M. Magureanu, A. Renken, L. Kiwi-minsker, Catalytic abatement of volatile organic compounds assisted by non-thermal 
plasma - Part 1. A novel dielectric barrier discharge reactor containing catalytic electrode, Applied Catalysis B: Environmental 65 (2006) 150-156. doi:10.1016/j.apcatb.2006.01.006.

[31] L. Sivachandiran, J. Karuppiah, C. Subrahmanyam, DBD plasma reactor for oxidative decomposition of chlorobenzene, International Journal of Chemical Reactor Engineering 10 (2012) 1-13. doi:10.1515/1542-6580.2785.

[32] M. Schmidt, M. Schiorlin, R. Brandenburg, Studies on the electrical behaviour and removal of toluene with a dielectric barrier discharge, Open Chemistry 13 (1) (2015) 477-483. doi:10.1515/chem-2015-0056.

[33] M. Schiorlin, E. Marotta, M. Rea, C. Paradisi, Comparison of toluene removal in air at atmospheric conditions by different corona discharges, Environmental Science and Technology 43 (24) (2009) 9386-9392. doi:10.1021/es9021816.

[34] W. A. Saoud, A. A. Assadi, M. Guiza, A. Bouzaza, W. Aboussaoud, A. Ouederni, I. Soutrel, D. Wolbert, S. Rtimi, Study of synergetic effect, catalytic poisoning and regeneration using dielectric barrier discharge and photocatalysis in a continuous reactor: Abatement of pollutants in air mixture system, Applied Catalysis B : Environmental 213 (2017) 53-61. doi:10.1016/j.apcatb.2017.05.012.

[35] M. Ragazzi, P. Tosi, E. Cristina, V. Torretta, M. Schiavon, Effluents from MBT plants : Plasma techniques for the treatment of VOCs, Waste Management 34 (11) (2014) 2400-2406. doi:10.1016/j.wasman.2014.07.026. 
[36] M. Prantsidou, J. C. Whitehead, The Chemistry of Gaseous Dodecane Degradation in a $\mathrm{BaTiO}_{3}$ Packed-Bed Plasma Reactor, Plasma Chemistry and Plasma Processing 35 (2015) 159-172. doi:10.1007/s11090-014-9597-2.

[37] A. Ogata, K. Saito, H. H. Kim, M. Sugasawa, H. Aritani, H. Einaga, Performance of an ozone decomposition catalyst in hybrid plasma reactors for volatile organic compound removal, Plasma Chemistry and Plasma Processing 30 (1) (2010) 33-42. doi:10.1007/s11090-009-9206-y.

[38] A. Ogasawara, J. Han, K. Fukunaga, J. Wang, D. Wang, T. Namihira, M. Sasaki, H. Akiyama, P. Zhang, Decomposition of Toluene Using Nanosecond-Pulsed-Discharge Plasma Assisted with Catalysts, IEEE Transactions on Plasma Science 43 (10) (2015) 3461-3469. doi:10.1109/TPS.2015.2447273.

[39] C. Norsic, J.-M. Tatibouët, C. Batiot-Dupeyrat, E. Fourré, Non thermal plasma assisted catalysis of methanol oxidation on $\mathrm{Mn}$, $\mathrm{Ce}$ and $\mathrm{Cu}$ oxides supported on $\gamma-\mathrm{Al}_{2} \mathrm{O}_{3}$, Chemical Engineering Journal 304 (2016) 563-572. doi:10.1016/j.cej.2016.06.091.

[40] Y. S. Mok, I.-S. Nam, Modeling of pulsed corona discharge process for the removal of nitric oxide and sulfur dioxide, Chemical Engineering Journal 85 (1) (2002) 87-97. doi:10.1016/S1385-8947(01)00221-2.

[41] M. Magureanu, N. B. Mandache, V. I. Parvulescu, Chlorinated organic compounds decomposition in a dielectric barrier discharge, Plasma Chem- 
istry and Plasma Processing 27 (6) (2007) 679-690. doi:10.1007/s11090007-9103-1.

[42] S. Lovascio, N. Blin-Simiand, L. Magne, F. Jorand, S. Pasquiers, Experimental Study and Kinetic Modeling for Ethanol Treatment by Air Dielectric Barrier Discharges, Plasma Chemistry and Plasma Processing 35 (2) (2015) 279-301. doi:10.1007/s11090-014-9601-x.

[43] E. H. Lock, A. V. Saveliev, L. A. Kennedy, Methanol and Dimethyl Sulfide Removal by Pulsed Corona Part I: Experiment, Plasma Chemistry and Plasma Processing 26 (6) (2006) 527-542. doi:10.1007/s11090-006-9011-9.

[44] Y. N. Liu, L. Braci, S. Cavadias, S. Ognier, Post-discharge treatment of air effluents polluted by butyl-mercaptan: the role of nitrate radical, Journal of Physics D: Applied Physics 44 (095202) (2011) 1-8. doi:10.1088/0022$3727 / 44 / 9 / 095202$.

[45] O. Koeta, Élimination de polluants par plasmas froids et association à la catalyse : Acétaldéhyde et Phénol, Thse de doctorat, Université Paris-Sud (2015).

[46] H.-H. Kim, A. Ogata, S. Futamura, A. Tio, Effect of Different Catalysts on the Decomposition of VOCs Using Flow-Type Plasma-Driven Catalysis, IEEE Transaction on Plasma Science 34 (3) (2006) 984-995.

[47] H.-H. Kim, Y.-H. Lee, A. Ogata, S. Futamura, Plasma-driven catalyst processing packed with photocatalyst for gas-phase benzene decomposi- 
tion, Catalysis Communications 4 (2003) 347-351. doi:10.1016/S15667367(03)00086-4.

[48] J. Karuppiah, L. Sivachandiran, R. Karvembu, C. Subrahmanyam, Catalytic nonthermal plasma reactor for the abatement of low concentrations of isopropanol, Chemical Engineering Journal 165 (1) (2010) 194-199. doi:10.1016/j.cej.2010.09.017.

[49] O. Karatum, M. A. Deshusses, A comparative study of dilute VOCs treatment in a non-thermal plasma reactor, Chemical Engineering Journal 294 (2016) 308-315. doi:10.1016/j.cej.2016.03.002.

[50] J.-O. Jo, S. B. Lee, D. L. Jang, Y. S. Mok, Plasma-Catalytic Ceramic Membrane Reactor for Volatile Organic Compound Control, IEEE Transaction on Plasma Science 41 (10) (2013) 3021-3029.

[51] Q. Jin, B. Jiang, J. Han, S. Yao, Hexane decomposition without particle emission using a novel dielectric barrier discharge reactor filled with porous dielectric balls, Chemical Engineering Journal 286 (2016) 300-310. doi:10.1016/j.cej.2015.10.070.

[52] N. Jiang, J. Hu, J. Li, K. Shang, N. Lu, Y. Wu, Plasma-catalytic degradation of benzene over AgCe bimetallic oxide catalysts using hybrid surface/packed-bed discharge plasmas, Applied Catalysis B : Environmental 184 (2016) 355-363.

[53] N. Jiang, J. Li, K. Shang, N. Lu, Y. Wu, Enhanced Degradation of Benzene 
in Surface/Packed-Bed Hybrid Discharge System: Optimization of the Reactor Structure and Electrical Parameters, IEEE Transactions on Plasma Science 44 (4) (2016) 657-664.

[54] H. Jiang, T. Shao, C. Zhang, P. Yan, Z. Niu, Y. Zhou, Effect of Grounded Electrode's Width on Electrical Characteristics of Nanosecond-pulse Surface DBD, in: Annual Report Conference on Electrical Insulation and Dielectric Phenomena, 2013, pp. 1030-1033.

[55] J. Jarrige, Etude expérimentale des décharges électriques Impulsionnelles nanoseconde à pression atmosphérique. Application au traitement des effluents gazeux et à la décontamination de surface, Phd thesis, Université de Rouen (2008).

[56] J. Jarrige, P. Vervisch, Decomposition of gaseous sulfide compounds in air by pulsed corona discharge, Plasma Chemistry and Plasma Processing 27 (3) (2007) 241-255. doi:10.1007/s11090-007-9049-3.

[57] J. Hu, N. Jiang, J. Li, K. Shang, N. Lu, Y. Wu, Degradation of benzene by bipolar pulsed series surface/packed-bed discharge reactor over $\mathrm{MnO}_{2}$ $\mathrm{TiO}_{2}$ /zeolite catalyst, Chemical Engineering Journal 293 (2016) 216-224. doi:10.1016/j.cej.2016.02.036.

[58] A. M. Harling, D. J. Glover, J. C. Whitehead, K. Zhang, Novel method for enhancing the destruction of environmental pollutants by the combination of multiple plasma discharges, Environmental Science and Technology 42 (12) (2008) 4546-4550. doi:10.1021/es703213p. 
[59] T. Guo, X. Li, J. Li, Z. Peng, L. Xu, J. Dong, On-line quantification and human health risk assessment of organic by-products from the removal of toluene in air using non-thermal plasma, Chemosphere 194 (2018) 139-146. doi:10.1016/j.chemosphere.2017.11.173.

[60] O. Guaïtella, Nature de la synergie plasma-photocatalyseur pour la destruction d'un composé organique volatil type : l'acétylène, Thse de doctorat, Ecole Polytechnique (2010).

[61] M. S. Gandhi, A. Ananth, Y. Sun, J.-I. Song, K.-H. Park, Time dependence of ethylene decomposition and byproducts formation in a continuous flow dielectric-packed plasma reactor, Chemosphere 91 (5) (2013) 685-691. doi:10.1016/j.chemosphere.2013.01.060.

[62] M. S. Gandhi, Y. S. Mok, S. B. Lee, H. Park, Effect of various parameters for butane decomposition under ambient temperature in a dielectric barrier discharge non-thermal plasma reactor, Journal of the Taiwan Institute of Chemical Engineers 44 (5) (2013) 786-794. doi:10.1016/j.jtice.2013.01.016.

[63] W. Faider, S. Pasquiers, N. Blin-Simiand, L. Magne, Role of quenching of metastable states in acetaldehyde decomposition by a non-equilibrium nitrogen plasma at sub-atmospheric pressure, Journal of Physics D: Applied Physics 46 (10) (2013) 1-16. doi:10.1088/0022-3727/46/10/105202.

[64] B. Dou, J. Li, W. Liang, T. Zhu, Y. Li, Y. Jin, L. He, Volatile Organic Compounds (VOCs) Removal by Using Dielectric Barrier Discharge, 2008 
2nd International Conference on Bioinformatics and Biomedical Engineering (2008) 3945-3948doi:10.1109/ICBBE.2008.488.

[65] G. Costa, A. A. Assadi, S. G.-a. Ghaida, A. Bouzaza, D. Wolbert, Study of butyraldehyde degradation and by-products formation by using a surface plasma discharge in pilot scale : Process modeling and simulation of relative humidity effect, Chemical Engineering Journal 307 (2017) 785-792. doi:10.1016/j.cej.2016.07.099.

[66] A. S. Chiper, N. Blin-Simiand, M. Heninger, H. Mestdagh, P. Boissel, F. Jorand, J. Lemaire, J. Leprovost, S. Pasquiers, G. Popa, C. Postel, Detailed Characterization of 2-Heptanone Conversion by Dielectric Barrier Discharge in $\mathrm{N}_{2}$ and $\mathrm{N}_{2} / \mathrm{O}_{2}$ Mixtures, Journal of Physical Chemistry A 114 (1) (2010) 397-407. doi:10.1021/jp907295d.

[67] C. L. Chang, T. S. Lin, Decomposition of toluene and acetone in packed dielectric barrier discharge reactors, Plasma Chemistry and Plasma Processing 25 (3) (2005) 227-243. doi:10.1007/s11090-004-3034-x.

[68] N. Blin-Simiand, S. Pasquiers, L. Magne, Removal of formaldehyde by a pulsed dielectric barrier discharge in dry air in the $20^{\circ} \mathrm{C}$ to $300^{\circ} \mathrm{C}$ temperature range, Journal of Physics D: Applied Physics 49 (195202) (2016) 1-12. doi:10.1088/0022-3727/49/19/195202.

[69] N. Blin-Simiand, S. Pasquiers, F. Jorand, C. Postel, J.-R. Vacher, Removal of formaldehyde in nitrogen and in dry air by a DBD: importance of temper- 
ature and role of nitrogen metastable states, Journal of Physics D: Applied Physics 42 (122003) (2009) 1-5. doi:10.1088/0022-3727/42/12/122003.

[70] N. Blin-Simiand, F. Jorand, S. Pasquiers, C. Postel, Influence of Temperature on the Removal of Toluene by Dielectric Barrier Discharge, International Journal of Plasma Environmental Science \& Technology 1 (1) (2007) 64-70.

[71] O. Aubry, J. M. Cormier, Improvement of the Diluted Propane Efficiency Treatment Using a Non-thermal Plasma, Plasma Chemistry and Plasma Processing 29 (2009) 13-25. doi:10.1007/s11090-008-9161-z.

[72] A. A. Assadi, A. Bouzaza, C. Vallet, D. Wolbert, Use of DBD plasma, photocatalysis, and combined DBD plasma/photocatalysis in a continuous annular reactor for isovaleraldehyde elimination - Synergetic effect and byproducts identification, Chemical Engineering Journal 254 (2014) 124132. doi:10.1016/j.cej.2014.05.101.

[73] A. A. Abdelaziz, T. Seto, M. Abdel-Salam, Y. Otani, Performance of a surface dielectric barrier discharge based reactor for destruction of naphthalene in an air stream, Journal of Physics D: Applied Physics 45 (2012) 115201. doi:10.1007/s11090-014-9578-5.

[74] A. S. Chiper, F. Jorand, S. Pasquiers, G. Popa, C. Postel, Influence of water vapour on acetaldehyde removal efficiency by DBD, Journal of Optoelectronics and Advanced Materials 8 (1) (2006) 208-211. 
[75] R. Aerts, X. Tu, W. V. Gaens, J. C. Whitehead, A. Bogaerts, Gas Purification by Nonthermal Plasma: A Case Study of Ethylene, Environmental Science and Technology 47 (2013) 6478-6485.

[76] S. Delagrange, L. Pinard, J.-m. Tatiboue, Combination of a non-thermal plasma and a catalyst for toluene removal from air : Manganese based oxide catalysts, Applied Catalysis B: Environmental 68 (2006) 92-98. doi:10.1016/j.apcatb.2006.07.002.

[77] J.-o. Chae, S.-i. Moon, H.-s. Sun, K.-y. Kim, V. A. Vassiliev, E. M. Mikholap, A Study of Volatile Organic Compounds Decomposition with the Use of Non-Thermal Plasma, KSME International Journal 13 (9) (1999) 647655.

[78] H.-x. Ding, A.-m. Zhu, X.-f. Yang, C.-h. Li, Removal of formaldehyde from gas streams via packed-bed dielectric barrier discharge plasmas, Journal of Physics D: Applied Physics 38 (2005) 4160-4167. doi:10.1088/0022$3727 / 38 / 23 / 004$.

[79] W.-j. Liang, J. Li, J.-x. Li, T. Zhu, Y.-q. Jin, Formaldehyde removal from gas streams by means of $\mathrm{NaNO}_{2}$ dielectric barrier discharge plasma 175 (2010) 1090-1095. doi:10.1016/j.jhazmat.2009.10.034.

[80] X. Zhu, X. Gao, R. Qin, Y. Zeng, R. Qu, C. Zheng, Plasma-catalytic removal of formaldehyde over $\mathrm{Cu}$ - Ce catalysts in a dielectric barrier discharge reactor, Applied Catalysis B: Environmental 170-171 (2015) 293300. doi:10.1016/j.apcatb.2015.01.032. 
[81] M. Sobacchi, a.V. Saveliev, A. Fridman, A. Gutsol, L. Kennedy, Experimental assessment of pulsed corona discharge for treatment of VOC emissions, Plasma chemistry and plasma processing 23 (2) (2003) 347-370. doi:10.1023/A:1022976204132.

[82] A. Rohatgi, WebPlotDigitizer, https://automeris.io/WebPlotDigitizer, consulté le : 29/06/2018.

[83] NIST Chemical Kinetics Database, https://kinetics.nist.gov, consulté le : 18/04/2018.

[84] T. Hastie, R. Tibshirani, J. Friedman, The Elements of Statistical Learning, Springer, New York, 2001.

[85] J. Perktold, S. Seabold, J. Taylor, About Statsmodels, http://www.statsmodels.org/dev/about.html, consulté le : $16 / 05 / 2018$.

[86] N. Mericam-Bourdet, M. Kirkpatrick, D. Frochot, E. Odic, F. Tuvache, Eco-efficient electrical and innovative technology development for indoor air and gas exhaust treatment in industry, ECEE 2011 Summer Study (2011) 715-723.

[87] O. Koeta, N. Blin-Simiand, W. Faider, S. Pasquiers, A. Bary, F. Jorand, Decomposition of acetaldehyde in atmospheric pressure filamentary nitrogen plasma, Plasma Chemistry and Plasma Processing 32 (5) (2012) 9911023. doi:10.1007/s11090-012-9388-6. 
[88] L. Mao, Z. Chen, X. Wu, X. Tang, S. Yao, X. Zhang, B. Jiang, J. Han, Z. Wu, H. Lu, T. Nozaki, Plasma-catalyst hybrid reactor with $\mathrm{CeO}_{2} / \gamma$ $\mathrm{Al}_{2} \mathrm{O}_{3}$ for benzene decomposition with synergetic effect and nano particle by-product reduction, Journal of Hazardous Materials 347 (2018) 150-159. doi:10.1016/j.jhazmat.2017.12.064.

[89] H.-H. Kim, Y. Teramoto, N. Negishi, A. Ogata, A multidisciplinary approach to understand the interactions of nonthermal plasma and catalyst: A review, Catalysis Today 256 (2015) 13-22. doi:10.1016/j.cattod.2015.04.009. 


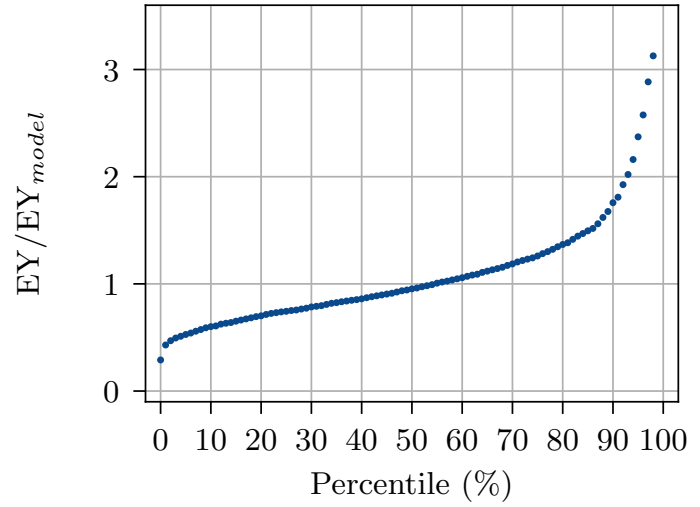

Figure 3: Percentiles of the ratio between the values of the energy yield calculated for each data point $(\mathrm{EY})$ and predicted by the model $\left(\mathrm{EY}_{\text {model }}\right)$. 